\title{
Model Pemberdayaan Laboratorium Bank Mini Syariah di Perguruan Tinggi
}

\author{
Eva Fauziah $^{1}$, Ifa Hanifia Senjiati ${ }^{2}$, Sandi Rizki Febriadi ${ }^{3}$ \\ ${ }_{1,2,3}$ Universitas Islam Bandung \\ 1evafmawardi@gmail.com; 2Ifa.wahyudin@gmail.com; 3prisha587@yahoo.com
}

\begin{abstract}
Sharia Mini Bank Laboratory is a medium to implement Tri Dharma of College which is expected to contribute to accelerate the development of sharia in Indonesia. Therefore, empowerment of laboratory of bank mini syariah as a place to develop competence in intellectual, motor skill and skill to use Islamic banking tools for increasing the competence of graduate and sharia banking students need to be reviewed. This is a qualitative research. Method of collecting data is using deep data observation technique. Data analysis is using spradley model domain analysis. The results showed that the model of empowerment of Mini Sharia Bank laboratory in Higher Education has four models; they are 1) model of secondary empowerment, 2) model primary internal empowerment of student, 3) model of primary internal empowerment of student and lecturer and 4) model of primary eksternal empowerment. This laboratory empowerment model is based on observations at four universities in Java, namely Bandung Islamic University (UNISBA), Islamic University of Malang (UNISMA), UIN Malang and UIN Sunan Ampel Surabaya.
\end{abstract}

Keywords: empowerment model, sharia mini bank laboratory, college

\begin{abstract}
Abstrak
Laboratorium Bank Mini Syariah merupakan sarana penunjang dan pelaksana program Tri Dharma Perguruan Tinggi yang diharapkan mampu memberikan kontribusi untuk mengakselerasi perkembangan syariah di Indonesia. Oleh karena itu, pemberdayaan laboratorium Bank Mini Syariah sebagai tempat mengembangkan kompetensi baik dalam bidang intelektual, ketrampilan motorik dan terampil memggunakan alat-alat media perbankan syariah untuk peningkatan kompetensi mahasiswa lulusan keuangan dan perbankan syariah perlu ditelaah. Metode penelitian menggunakan metode kualitatif dengan teknik pengumpulan data observasi mendalam. Analisis data menggunakan analisis domain model spradley. Hasil penelitian menunjukkan bahwa model pemberdayaan laboratorium Bank Mini Syariah di Perguruan Tinggi memiliki empat model yaitu 1). Model pemberdayaan sekunder, 2). Model pemberdayaan primer internal mahasiswa, 3). Model pemberdayaan primer internal mahasiswa dan dosen, dan 4). Model pemberdayaan primer eksternal. Model pemberdayaan laboratorium ini berdasarkan pengamatan pada empat perguruan tinggi di Jawa yaitu Universitas Islam Bandung, Universitas Islam Malang, UIN Malang dan UIN Sunan Ampel Surabaya.
\end{abstract}

Kata kunci: Model Pemberdayaan, Laboratorium Bank Mini Syariah, perguruan tinggi 


\section{PENDAHULUAN}

Perkembangan dan pertumbuhan lembaga keuangan syariah baik lembaga keuangan bank maupun lembaga keuangan non bank di Indonesia mengalami peningkatan. Salah satunya ditandai dengan peningkatan jumlah lembaga keuangan bank dan non bank serta total aset yang dimiliki. Tercatat pada data statistik Otoritas Jasa Keuangan (OJK), jumlah Bank Umum Syariah (BUS) tahun 2008 sebanyak 3 bank dan pada bulan Juli 2017 bertambah menjadi 13 BUS yaitu Bank Muamalat, BNI Syariah, BRI Syariah, BTPN Syariah, Bukopin Syariah, Bank Mandiri Syariah, Bank Panin Syariah, Bank Mega Syariah, Bank Victoria Syariah, Bank Jabar Banten Syariah, BCA Syariah, Bank Maybank Syariah, dan terakhir yang bergabung adalah Bank Aceh Syariah. Unit Usaha Syariah (UUS) pada awalnya berjumlah 28 unit saat ini menurun menjadi 21 unit karena beberapa dari UUS tersebut melakukan spin off dari bank induk. Sementara jumlah Bank Perkreditan Rakyat Syariah (BPRS) yang awalnya berjumlah 124 BPRS, per juli 2017 bertambah menjadi 167. Adapun total aset yang dimiliki Bank Umum Syariah per Juli 2017 sebesar 269.938 miliar, UUS sebesar 108.648 miliar, dan BPRS 9,912 triliun, sementara jumlah LKM menjadi 165 yang sudah mendapat izin operasional OJK termasuk LKMS yang di awal tahun 2017 berjumlah 14 untuk bulan Juli menjadi 18 LKMS dengan total aset LKM/S sebesar 300,01 miliar per Juli 2017 (ojk.go.id).

Perkembangan lembaga keuangan khususnya perbankan syariah perlu didukung supaya perbankan syariah di Indonesia dapat menjadi trendsetter keuangan syariah Asia. Namun salah satu kendalanya adalah ketersediaan sumber daya manusia yang berasal dari perguruan tinggi (Zuhroh, 2012). Menurut Alamsyah (2012), Deputi Gubernur Bank Indonesia, masih terdapat gap sumber daya insani baik secara kuantitas maupun kualitas. Kurikulum pendidikan dan keahlian di bidang keuangan syariah belum memadai, belum ada link and match antara industri keuangan dengan perguruan tinggi, kurang sosialisasi dan edukasi. Oleh karena itu, permasalahan ini ada kaitannya dengan peran perguruan tinggi dalam menghasilkan lulusan yang kompeten. Salah satu hal pokok dan penting dalam proses tersebut adalah adanya laboratorium yang dapat meningkatkan kompetensi lulusannya serta model pemberdayaannya.

Hasil dari beberapa penelitian menunjukkan bahwa laboratorium bank dapat menyokong kegiatan pengelolaan keuangan sekolah yang berdampak salah satunya kepada peningkatan kompetensi peserta didik (Ludviana, 2012). Pembelajaran praktikum laboratorium keuangan (bank mini) dengan variabel kerumitan aplikasi, fasilitas laboratorium, metode penyampaian bahan ajar berpengaruh signifikan terhadap peningkatan skill mahasiswa keuangan Islam UIN Sunan Kalijaga (Saifulloh, 2016). Perlu adanya penguatan terhadap kualitas laboratorium bank mini syariah yang dilakukan oleh perguruan tinggi (Zuhroh, 2012) atau dapat dilakukan melalui kerjasama dengan pihak lain sebagai bentuk simbiosis mutualisme untuk mewujudkan SDM ekonomi yang lebih beradab ke depan (Istikanah, 2014). Oleh karena itu, laboratorium bank mini syariah di perguruan tinggi selain sebagai sarana penopang dan pelaksanaan program Tri Dharma Perguruan Tinggi juga dapat menyokong dan memberikan kontribusi akselerasi perkembangan perbankan syariah di Indonesia.

Model diartikan sebagai representasi dari suatu objek, benda, atau ide-ide dalam bentuk yang disederhanakan dari kondisi atau fenomena alam. Model berisi informasiinformasi tentang suatu fenomena yang dibuat dengan tujuan untuk mempelajari 
fenomena sistem yang sebenarnya. Menurut Achmad (dalam Caralay, 2014) model dapat merupakan tiruan dari suatu benda, sistem atau kejadian yang sesungguhnya yang hanya berisi informasi-informasi yang dianggap penting untuk ditelaah. Bentuk model secara umum ada empat, yaitu model sistem, model mental, model verbal, dan model matematika. Model sistem adalah alat yang kita gunakan untuk menjawab pertanyaan pertanyaan tentang sistem tanpa melakukan percobaan. Model mental adalah modelmodel untuk sistem teknik yang berdasarkan pada pengalaman dan perasaan. Model verbal adalah sebuah model perilaku sistem pada kondisi yang berbeda dideskripsikan dengan kata-kata. Dan model matematika yaitu dimana kita menghubungkan antara besaran (jarak, arus, aliran pengganguran dan lain sebagainya) yang dapat kita amati pada sistem, dideskripsikan sebagai hubungan matematikal dalam model.

Majid (2013) mengungkapkan bahwa secara umum model diartikan sebagai kerangka konseptual yang digunakan sebagai pedoman dalam melakukan suatu kegiatan. Dalam pengertian lain, model juga diartikan sebagai barang atau benda sesungguhnya, seperti "globe" yang merupakan model dari bumi tempat kita hidup.

Pemberdayaan dalam Kamus Besar Bahasa Indonesia adalah upaya membuat sesuatu berkemampuan atau berkekuatan. Menurut Gunawan (dalam Sumodiningrat, 1997) pemberdayaan adalah upaya untuk membangun daya yang dimiliki dengan mendorong, memberikan motivasi, dan meningkatkan kesadaran tentang potensi yang dimiliki serta berupaya untuk mengembangkannya. Pemberdayaan pada hakikatnya merupakan sebuah konsep yang fokusnya adalah hal kekuasaan. Oleh karena itu, menurut Adimihardja \& Hikmat (2001) kata pemberdayaan mengesankan arti tangguh atau kuat. Dubois \& Miley (dalam Adimihardja \& Hikmat, 2001) menyatakan bahwa proses pemberdayaan adalah:

a). Mempersiapkan kerja sama;

b). Menjalin relasi kemitraan;

c). Mengartikulasikan tantangan-tantangan;

d). Mengidentifikasi berbagai kekuatan yang ada;

e). Mendefinisikan arah yang ditetapkan;

f). Mengeksplorasi sistem-sistem sumber;

g) Menganalisis kapasitas sumber;

h) Menyusun kerangka pemecahan masalah;

i) Mengoptimalkan pemanfaatan sumber;

j) Memperluas kesempatan-kesempatan

k) Mengakui keberhasilan; dan

1) Mengintegrasikan kemajuan-kemajuan yang dicapai.

Berikutnya, masih menurut Adimihardja \& Hikmat (2001), proses pemberdayaan mengandung dua kecenderungan, yaitu:

a. Pemberdayaan yang menekankan pada proses memberikan atau mengalihkan sebagian kekuasaan, kekuatan atau kemampuan kepada masyarakat agar individu menjadi lebih berdaya. Pada proses ini dapat dilengkapi dengan upaya membangun aset material untuk mendukung pembangunan kemandirian melalui organisasi. Proses pada pemberdayaan ini merupakan kecenderungan primer dari pemberdayaan.

b. Pemberdayaan yang menekankan pada proses menstimulasi, mendorong atau memotivasi agar individu atau lembaga mempunyai kemampuan atau keberdayaan 
untuk menentukan apa yang menjadi pilihan hidupnya melalui proses dialog. Pemberdayaan pada proses ini merupakan kecenderungan pemberdayaan sekunder.

Menurut Sumodiningrat (dalam Hadi, 2015) bahwa dua kecenderungan proses pemberdayaan tersebut memberikan pada titik ekstrem. Seolah keduanya pada dua sisi diametral yang berseberangan. Akan tetapi, pada dasarnya untuk mewujudkan kecenderungan primer harus melalui kecenderungan sekunder terlebih dahulu.

Menurut Kamus Umum Bahasa Indonesia, laboratorium adalah tempat untuk mengadakan percobaan (penyelidikan) segala sesuatu yang berhubungan dengan ilmu fisika, kimia dan sebagainya. Menurut Hornby (2010) "laboratory is a room or building used scientific research, experiments, testing, etc". Artinya adalah ruangan atau bangunan yang digunakan penelitian ilmiah, eksperimen, pengujian dan lain-lain.

Laboratorium adalah tempat, ruang atau kamar tertentu yang dilengkapi dengan percobaan (penyelidikan dan sebagainya). Dapat juga diartikan sebagai unit penunjang akademik pada lembaga pendidikan yang dikelola secara sistematis untuk kegiatan pengujian, kalibrasi dan atau produksi dalam skala terbatas dengan menggunakan peralatan dan bahan berdasarkan metode keilmuan tertentu dalam rangka pelaksanaan pendidikan, penelitian, dan atau pengabdian kepada masyarakat. Di samping itu, laboratorium pun dapat berfungsi sebagai pelayanan masyarakat (Saifulloh, 2016).

Menurut kegunaannya, laboratorium dibagi menjadi dua jenis yaitu laboratorium pembelajaran (classroom laboratory) dan laboratorium penelitian (research laboratory). Laboratorium pembelajaran didesain untuk proses belajar mengajar, praktikum dan kegiatan lain yang mendukung proses pembelajaran (Hamdani \& Kurniatanty, 2008). Adapun fungsi laboratorium antara lain:

a. Sebagai tempat berlangsungnya kegiatan pembelajaran secara praktik yang memerlukan peralatan khusus,

b. Sebagai tempat yang mendorong semangat peserta didik untuk memperdalam pengertian suatu fakta yang diselidiki atau diamati,

c. Tempat display atau pameran,

d. Sebagai tempat untuk belajar memahami karakteristik alam dan lingkungan melalui optimalisasi keterampilan proses serta mengembangkan sikap ilmiah,

e. Sebagai tempat berlatih menerapkan proses sesuai dengan tuntutan pembelajaran yang mengutamakan proses selain produk,

f. Memberikan kelengkapan bagi mata kuliah teori yang diterima sehingga ada harmonisasi antara teori dan praktik.

Laboratorium bank mini syariah adalah tempat melakukan kegiatan laboratorium perbankan syariah yang diselenggarakan di prodi ekonomi/ekonomi syariah, keuangan perbankan syariah atau muamalah untuk meningkatkan kompetensi mahasiswa pada bidang perbankan syariah yang memadukan pengetahuan dan praktis dalam suatu kegiatan bank syariah yang terintegrasi. Artinya, pengetahuan yang diperoleh selama perkuliahan dipraktikkan di laboratorium. Dalam proses pembelajaran di laboratorium bank mini, kegiatannya menyerupai kegiatan bank syariah pada umumnya, antara lain: menginput data nasabah, membuat CIF, melayani transaksi simpan dan tarik, dan lain-lain. Dengan demikian, mahasiswa diajarkan bagaimana menjalankan kegiatan di perbankan syariah seperti penginputan, transaksi di teller, melakukan funding, financing, service dan kegiatan-kegiatan lain yang bersifat sosial (tabarru') dan lain-lain. 
Selain itu, laboratorium bank mini syariah juga dapat diberdayakan menjadi laboratorium untuk melakukan transaksi riil. Artinya, laboratorium tersebut bisa menjadi tempat transaksi riil baik dalam penghimpunan dana maupun dalam penyaluran dana namun terbatas pada civitas akademika atau dapat pula diperluas cakupan kerjanya ke masyarakat luar kampus apabila sudah mendapat izin operasional dari pihak OJK, yang kemudian dapat menjadi unit usaha dari Laboratorium/Prodi/Fakultas yang bersangkutan serta dapat pula bekerja sama dengan lembaga keuangan lain di luar kampus. Hasil penelitian Ghofur (2015) yang berjudul "Dampak Kemitraan Bank Syariah Mandiri Cabang Gresik terhadap Kinerja BMT (Studi Kasus BMT Mandiri Sejahtera Kabupaten Gresik)" menerangkan bahwa kinerja keuangan berupa return on Asset (ROA), Return On Equity (ROE), Non Performing Financing (NPF), Financing to Deposit rasio (FDR) dan kinerja sosial berupa Zakat, Infak, Shodaqah (ZIS) serta Qardhul Hasan menunjukkan dampak positif terhadap kinerja BMT Mandiri Syariah Sejahtera setelah bermitra dengan Bank Syariah Mandiri Cabang Gresik. Dengan demikian, laboratorium bank mini syariah mempunyai dua fungsi yaitu sebagai bagian yang terintegrasi dari pendidikan dan pengajaran serta sebagai pelayanan masyarakat. Oleh karena itu, dalam operasionalnya terdapat mahasiswa yang ditugaskan untuk mengelola laboratorium bank mini syariah sebagai Baitul Maal wa Tamwiil (BMT) baik sebagai pengurus dan atau yang ditugaskan magang untuk mengoperasikan bank mini tersebut.

Tugas yang diberikan kepada mahasiswa pengelola BMT bank mini syariah adalah tugas sebagai Customer Service (CS), Teller, bagian pemasaran, bagian penghimpunan dana, bagian analisis pembiayaan dan lain-lain. Laboratorium BMT bank mini berfungsi sebagai wahana pengumpulan dana dari seluruh civitas akademika untuk kemudian disalurkan melalui pembiayaan kepada civitas akademika pula yang mengajukan produk pembiayaan. Dengan demikian, laboratorium bank mini syariah dapat menciptakan mahasiswa yang memiliki daya saing yang ke depannya dapat menjadi praktisi yang profesional.

Tulisan ini mengkaji model pemberdayaan laboratorium bank mini syariah di perguruan tinggi karena peran laboratorium sangat penting dalam menyediakan sumber pembelajaran tentang bank syariah melalui maksimalisasi pemberdayaan laboratorium bank mini syariah di perguruan tinggi. Model pemberdayaan berkaitan dengan fisik bangunan, sumber daya manusia, kemampuan SDM, proses pemberdayaan dan pada akhirnya lembaga tersebut akan berdaya. Pemberdayaan laboratorium bank mini syariah memerlukan model, supaya kegiatan pemberdayaan lebih sistematis dan terstruktur, bukan hanya peningkatan sumber daya manusia saja namun berdaya secara keseluruhan. Berdasarkan paparan tersebut maka tujuan penelitian ini untuk menggambarkan model pemberdayaan laboratorium bank mini syariah di perguruan tinggi.

\section{METODOLOGI}

Tulisan ini bertujuan untuk memperoleh gambaran tentang pemberdayaan laboratorium bank mini syariah di perguruan tinggi. Metode yang digunakan adalah deskriptif kualitatif yang memaparkan model pemberdayaan laboratorium bank mini syariah di perguruan tinggi. Metode penelitian kualitatif dapat diartikan sebagai metode penelitian yang berlandaskan pada filsafat postpositivisime, digunakan untuk meneliti pada kondisi objek yang alamiah, dimana peneliti sebagai instrumen kunci, 
teknik pengumpulan data dilakukan secara triangulasi (gabungan), analisis data bersifat induktif/kualitatif, dan hasil penelitian kualitatif lebih menekankan makna dari pada generalisasi (Sugiyono, 2015).

Variabel penelitian yang menjadi fokus dalam penelitian ini adalah pemberdayaan laboratorium bank mini syariah. Adapun observasi yang digunakan dalam penelitian adalah mengamati model pemberdayaan laboratorium bank mini syariah yang dilakukan oleh perguruan tinggi. Pengumpulan data pada penelitian kualitatif dilakukan dengan natural setting (kondisi alamiah), sumber data primer, observasi dan wawancara secara mendalam. observasi partisipatif yaitu peneliti datang di tempat kegiatan orang yang diamati, tetapi tidak ikut terlibat dalam kegiatan tersebut. Tahapan observasi yang dilakukan yaitu observasi deskriptif, reduksi dan seleksi.

Pengumpulan data yang dilakukan dalam penelitian ini adalah triangulasi data yang terdiri dari :

a. Observasi partisipatif: Dilakukan observasi mendalam ke laboratorium bank mini syariah di empat perguruan tinggi dengan cara partisipasi mengamati praktik yang dilakukan di objek penelitian tersebut.

b. Wawancara terstruktur: Dibantu dengan alat wawancara buku catatan, recorder menggunakan telepon genggam, dan kamera handphone. Wawancara dilakukan kepada kasi laboratorium syariah, mahasiswa, dan karyawan koperasi syariah.

c. Dokumentasi: Dokumen penunjang lainnya. Dokumentasi dilakukan dengan mendokumentasi contoh slip simpanan dan pembiayaan serta dokumen lainnya yang mendukung.

Tabel 1. Analisis Domain Model Spradley

\begin{tabular}{clcc}
\hline No & \multicolumn{1}{c}{ Included Term/rincian domain } & $\begin{array}{c}\text { Hubungan } \\
\text { semantik }\end{array}$ & $\begin{array}{c}\text { Cover term / } \\
\text { domain }\end{array}$ \\
\hline 1 & $\begin{array}{l}\text { Pengalihan kekuasaan, kekuatan, dan kemampuan } \\
\text { Menjadi Berdaya }\end{array}$ & $\begin{array}{l}\text { Adalah } \\
\text { elemen dari }\end{array}$ & $\begin{array}{l}\text { Pemberdayaan } \\
\text { Dapat membangun aset material untuk } \\
\text { pembangunan kemandirian }\end{array}$ \\
& $\begin{array}{l}\text { Dapat membentuk organisasi } \\
\text { Dapat menentukan pilihan kelangsungan hidup } \\
\text { Pengembangan keterampilan motorik }\end{array}$ & Adalah \\
& $\begin{array}{l}\text { Pengembangan kompetensi bidang intelektual } \\
\text { Pelayanan kepada masyarakat }\end{array}$ & fungsi dari & $\begin{array}{l}\text { Laboratorium } \\
\text { Bank Mini } \\
\text { syariah }\end{array}$ \\
\hline
\end{tabular}

Penelitian ini menggunakan analisis model Spradley (2007) yang dapat dijabarkan sebagai berikut:

a. Analisis domain: Memperoleh gambaran umum secara menyeluruh.

b. Analisis taksonomi: Penjabaran lebih rinci dari domain yang ada yang dilakukan dengan observasi terfokus.

c. Analisis komponensial: Mencari ciri spesifik pada setiap struktur internal dengan cara mengkontraskan antar elemen. Dilakukan melalui observasi dan wawancara terseleksi dengan pertanyaan yang menkontraskan.

d. Analisis tema kultural: Mencari hubungan di antara domain, dan bagaimana hubungan 
dengan keseluruhan, dan selanjutnya dinyatakan ke dalam tema penelitian.

\section{PEMBAHASAN}

Terdapat tiga pilar utama dalam pemberdayaan laboratorium bank mini syariah di perguruan tinggi, yaitu dosen, mahasiswa dan komunitas organisasi mahasiswa. Pilar dosen berfungsi memberikan arahan, membantu merumuskan dan memutuskan kebijakan yang sesuai dengan pengembangan model pemberdayaan laboratorium bank mini syariah di perguruan tinggi. Pilar komunitas/organisasi mahasiswa menjalankan fungsi sebagai penyadaran kritis kepada warga kampus perguruan tinggi yang bersangkutan untuk melakukan transaksi sesuai syariat Islam, dan pilar mahasiswa berfungsi sebagai subjek yang melaksanakan praktik transaksi syariah bersama-sama dengan dosen dan sekaligus sebagai objek dalam menjalankan kegiatannya. Ketiga pilar ini akan menentukan keberhasilan pemberdayaan laboratorium.

Mengacu kepada pendapat Dubois \& Miley (dalam Adimihardja \& Hikmat, 2001) terkait proses pemberdayaan secara umum maka pemberdayaan laboratorium bank mini syariah perguruan tinggi di UNISBA adalah sebagai berikut:

a. Mempersiapkan kerja sama. Laboratorium bank mini syariah bekerjasama dengan pihak lain dalam memberdayakan laboratorium seperti kerjasama dengan lembaga keuangan syariah. Kerjasama yang dilakukan oleh laboratorium bank mini syariah di UNISBA yaitu dengan Bank BRI Syariah dalam pengadaan software laboratorium bank mini yang disebut SALAM BRIS (Sistem Aplikasi Laboratorium Mini Banking BRISyariah)

b. Menjalin relasi kemitraan. Relasi kemitraan yang terjalin adalah antara laboratorium bank mini dengan petugas BMT. Mahasiswa yang memiliki nilai laboratorium bank mini yang sangat memuaskan maka berhak untuk mendaftarkan diri menjadi pengurus BMT.

c. Mengartikulasikan tantangan-tantangan. Tantangan yang dihadapi laboratorium bank mini syariah seperti menghadapi berbagai karakter dosen dan mahasiswa yang berbeda-beda.

d. Mengidentifikasi berbagai kekuatan yang ada. Kekuatan laboratorium bank mini syariah diantaranya adalah memiliki teknik pembelajaran simulasi aktif dengan mahasiswa melalui role play serta menggunakan software aplikasi yang sama persis dengan software aslinya seperti software SALAM BRIS dari Bank BRI Syariah.

e. Mendefinisikan arah yang ditetapkan. Arah yang ditetapkan oleh laboratorium bank mini syariah adalah memberikan tempat yang dapat meningkatkan kompetensi baik intelektual atau keterampilan menggunakan alat (seperti komputer) pada mahasiswa agar lebih siap guna bagi stakeholder (pengguna/user)

f. Mengeksplorasi sistem-sistem sumber. Eksplorasi sumber-sumber baik itu sumber pendanaan melalui dana corporate social responsibility atau melalui pengajuan ke perguruan tinggi sebagai dana operasional rutin (seperti di UNISBA terdapat dana rutin, dana ujian, dana supplies dan ATK). Adapun sumber daya manusia yaitu mendatangkan pengajar di laboratorium yang merupakan praktisi perbankan.

g. Menganalisis kapasitas sumber. Mengetahui kapasitas sumber daya yang dimiliki seperti kapasitas ruangan dengan jumlah mahasiswa yang tersedia, dan dosen 
pengajar yang tersedia yang akhirnya disusun jadwal kegiatan pembelajaran praktik bank mini syariah di kelas.

h. Menyusun kerangka pemecahan masalah. Masalah yang dihadapi akan dipecahkan dengan cara melakukan diskusi dengan pihak dekanat fakultas sebagai atasan dari ketua seksi laboratorium atau mengambil keputusan sendiri apabila permasalahan tidak terlalu rumit.

i. Mengoptimalkan pemanfaatan sumber. Sumber daya yang ada baik itu pengajar, mahasiswa dan peralatan laboratorium bank mini dapat diberdayakan dengan cara membuka pelatihan bagi masyarakat umum seperti mahasiswa dari perguruan tinggi lain atau siswa di sekolah menengah kejuruan yang berminat memahami proses bank syariah secara riil.

j. Memperluas kesempatan-kesempatan. Kesempatan dapat diperoleh dengan memperluas jaringan silaturahim ketua seksi laboratorium dengan stakeholder.

k. Mengakui keberhasilan. Keberhasilan akan bersifat relatif atau pencapaian akan disesuaikan dengan kegiatan yang dilakukan. Jika indikator tujuan terpenuhi maka dapat dikatakan berhasil.

1. Mengintegrasikan kemajuan-kemajuan yang dicapai. Kemajuan yang dicapai dapat diintegrasikan dengan kegiatan lain di perguruan tinggi sebagai media promosi fakultas dan perguruan tinggi bagi konsumen.

Adapun jika dilihat dari proses kecenderungan pemberdayaan laboratorium maka model pemberdayaan di perguruan tinggi swasta UNISBA termasuk kepada kategori proses pemberdayaan primer karena laboratorium bank mini syariah UNISBA memenuhi indikator dari proses pemberdayaan primer, yaitu:

1. Pengalihan kekuasaan, kekuatan, dan kemampuan

Fakultas dan Prodi memberikan kewenangan terhadap Kasi laboratorium untuk menjalankan proses pembelajaran pada tiap semesternya yang dibuktikan dengan memberikan kewenangan dalam :

a) Menentukan jadwal praktikum pada setiap semester dengan jumlah pertemuan sebanyak 12 kali ditambah satu kali ujian yaitu Ujian Akhir Semester (UAS).

b) Menentukan rencana anggaran proses pembelajaran yang didiskusikan dengan wakil Dekan II.

c) Mengajukan dan mengelola dana rutin, dana ujian, dana supplies dan dana ATK sesuai anggaran yang ditetapkan pada awal periode anggaran perguruan tinggi.

d) Menentukan dan membagi kelas pembelajaran laboratorium bank mini syariah sesuai dengan kapasitas ruangan dan alat yang tersedia. Adapun di laboratorium bank mini syariah UNISBA terdapat dua kelas dan masing-masing kelas terdiri dari 18 alat komputer sebagai penunjang pembelajaran laboratorium bank mini syariah.

e) Menentukan dosen dan asisten laboratorium yang mengajar di laboratorium bank mini syariah. Adapun dosen yang mengajar adalah dosen yang pernah mengikuti Training of Trainer (ToT) dari bank BRI Syariah, sedangkan asisten laboratorium adalah yang memiliki nilai sangat memuaskan pada saat ujian akhir semester. Bank BRI Syariah bekerjasama dengan laboratorium bank mini syariah UNISBA dalam penerapan program SALAM BRIS sebagai bentuk corporate social responsibility BRI Syariah kepada peningkatan pendidikan. 
Hal ini diperkuat dengan hasil penelitian Fauziah, Senjiati, \& Malik (2016) yang menyatakan bahwa pemberian software aplikasi mini banking SALAM BRIS terhadap perguruan tinggi ini berdasarkan pada hasil analisa terhadap kebutuhan dan tantangan dari dunia usaha. Dalam hal ini, rencananya mahasiswa diberikan bantuan akses dan kesempatan meningkatkan pengalaman sikap mental membangun kedewasaan, kemandirian, leadership, entrepreneurship, serta refleksi penerapan nilai-nilai keyakinan dan spiritual, dan terakhir terdapat berbagai intervensi program berupa serial pelatihan dan pendampingan reguler. Selain itu pula, pemberdayaan laboratorium bank mini syariah sejalan dan mendukung kegiatan roadmap Otoritas Jasa Keuangan pada bidang perbaikan kuantitas dan kualitas SDM poin 2 dan poin 3 yaitu terkait pengembangan standar kurikulum perbankan syariah di perguruan tinggi dan pemetaan kompetensi dan kajian standar kompetensi bankir syariah. Hal itu selaras dan mendukung kegiatan pada poin enam tentang pemberdayaan sektor riil bersama LKMS lainnya (Otoritas jasa Keuangan, 2015).

Selain pengalihan kemampuan di atas, terdapat pengalihan kemampuan dari dosen kepada mahasiswa mengenai praktik-praktik perbankan syariah melalui laboratorium bank mini syariah sehingga mahasiswa pengambil mata kuliah praktik laboratorium bank mini syariah memiliki kemampuan dan kompetensi dalam mengoperasionalkan sistem software perbankan syariah.
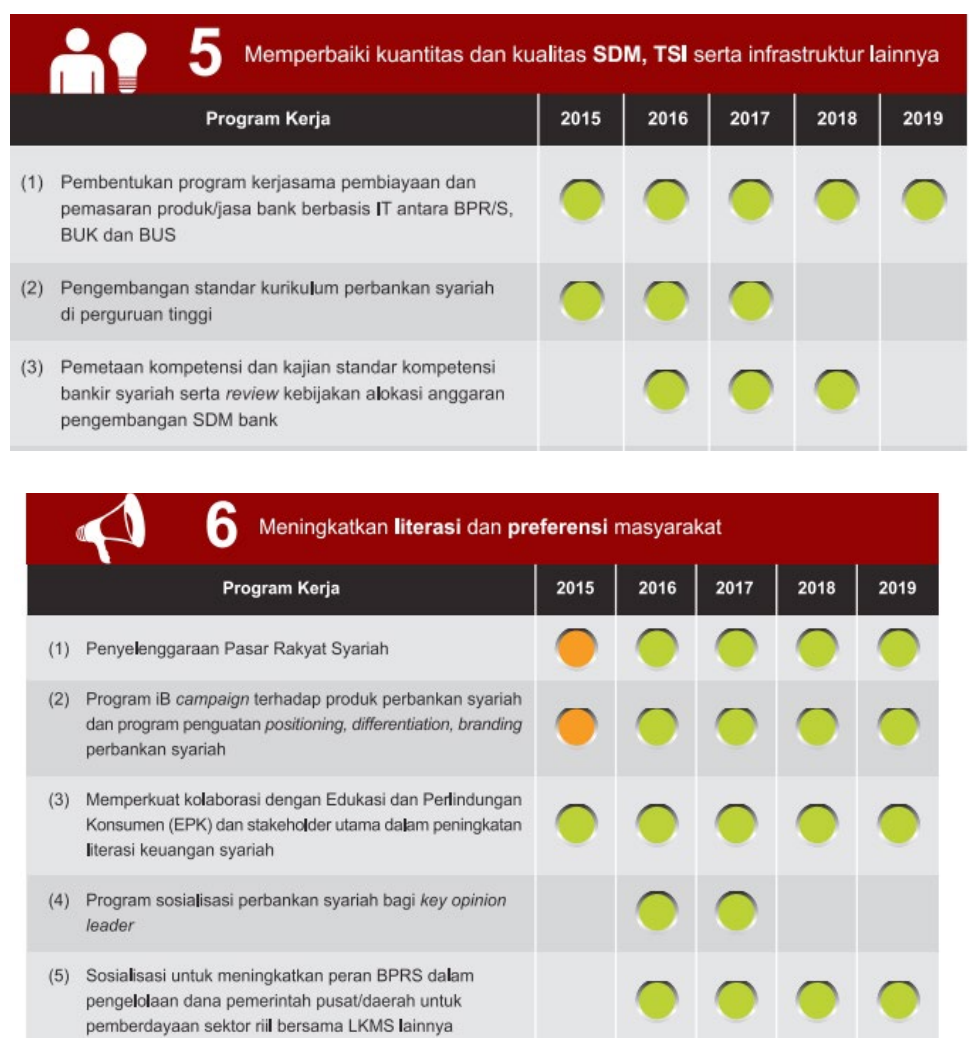

Gambar 1. Road Map Perbankan Syariah 2015-2019

Sumber : Otoritas jasa Keuangan (www.ojk.go.id) 
Indikator dari terjadinya proses pengalihan kemampuan kepada mahasiswa dapat dilihat dari dipersyaratkannya jumlah minimal pertemuan antara dosen dan mahasiswa sebesar $75 \%$. Apabila jumlah pertemuan kurang dari $75 \%$ mahasiswa dilarang mengikuti ujian praktikum laboratorium bank mini syariah. Selanjutnya, untuk mengukur kemampuan mahasiswa dilakukan tes di akhir semester dengan perolehan nilai minimal 60 poin. Apabila mahasiswa tidak dapat meraih nilai minimal 60 poin maka diwajibkan untuk mengulang dan mengikuti kembali kegiatan praktikum bank mini syariah pada tahun berikutnya.

2. Menjadi Berdaya

Kemampuan mahasiswa dalam mengoperasikan aplikasi perbankan syariah dapat dilihat dari tingkat nilai yang diperoleh mahasiswa. Nilai yang tertinggi adalah 100 poin dan nilai terendah yang dinyatakan lulus adalah 60 poin. Adapun indikator berdaya lainnya adalah mahasiswa yang telah mengambil mata kuliah laboratorium bank mini syariah dapat mendaftarkan diri menjadi petugas pembayaran kuliah yang diselenggarakan oleh perguruan tinggi sehingga mahasiswa memiliki daya jual yang tinggi, atau mahasiswa terbaik dapat menjadi pengurus BMT.

3. Dapat Membangun Aset Material Untuk Pembangunan Kemandirian

Laboratorium bank mini syariah UNISBA telah dapat membangun aset material untuk pembangunan kemandirian yang dapat diindikasikan dari :

a) Beberapa mahasiswa yang lulus praktik laboratorium bank mini syariah diambil pihak bank BRI Syariah untuk diperbantukan dalam melayani transaksi pembayaran uang kuliah pada setiap semester di UNISBA.

b) Hasil laporan mahasiswa yang melakukan Kuliah Kerja Lapangan (KKL) di beberapa industri lembaga keuangan baik bank maupun nonbank hampir $100 \%$ rata-rata mendapat nilai A (dengan passing grade nilai 80-100). Artinya, para mahasiswa tersebut telah berdaya dan mampu mandiri mengoperasionalkan praktik perbankan di dunia industri.

c) Aset material lain adalah laboratorium bank mini syariah dapat mendirikan BMT dan asetnya diperoleh dari simpanan wajib dan simpanan pokok mahasiswa

4. Dapat Membentuk Organisasi

Laboratorium bank mini syariah UNISBA sudah membentuk organisasi lembaga keuangan mikro yang dikelola mahasiswa yaitu BMT Fasya UNISBA. BMT ini didirikan secara resmi dan di-launching pada tanggal 21 April 2016 oleh Rektor UNISBA. Dana Pihak Ketiga (DPK) yang terkumpul sejak berdiri hingga bulan September 2017 sebesar Rp. 83.286.200,- Dana tersebut juga menjadi aset Laboratorium BMT bank mini syariah. Sumber dana ini berasal dari Rektor UNISBA Prof. DR. M.Taufik Boesoeri, M.Si., dr. Sp. THT. KL (K), Simpanan Pokok, Simpanan Wajib, Simpanan Sukarela dan lain-lain.

Adapun jumlah pembiayaaan yang telah disalurkan sebesar Rp. 35.325.200,kepada 14 (empat belas orang) mahasiswa dan dosen. Produk akad pembiayaan yang disalurkan menggunakan akad ijarah untuk jenis pembiayaan pendidikan, akad musyarakah untuk usaha mahasiswa, akad murabahah untuk usaha mahasiswa, pembelian barang, pembelian barang penunjang perkuliahan seperti laptop, handphone, hardisk eksternal dan lainnya. Mahasiswa dan dosen yang telah mendapatkan pembiayaan terkait pendidikan sebanyak 10 (sepuluh) orang dan masih dalam bentuk piutang sebesar Rp. 3.110.000,- Pada semester Ganjil tahun 2017-2018 ditambah kembali pembiayaan 
pendidikan sebesar Rp. 13.350.000,- yang diakses oleh 6 orang mahasiswa UNISBA.

5. Dapat Menentukan Pilihan Kelangsungan Hidup

Laboratorium bank mini syariah bekerjasama dengan dosen dan mahasiswa mengadakan pelatihan-pelatihan guna untuk memperpanjang kelangsungan hidup laboratorium bank mini syariah. Dari hasil kerjasama tersebut maka akan ada pendapatan dari menyewakan ruangan dan alat-alat laboratorium seperti komputer dan software di dalamnya. Program yang dilakukan dalam memperpanjang kelangsungan hidup laboratorium bank mini syariah diantaranya:

a) Mengadakan pelatihan bagi siswa atau mahasiswa

b) Mendirikan BMT

c) Menjual modul kepada mahasiswa

d) Menjual alat kalkulator kepada mahasiswa

Selain pemberdayaan yang dilakukan di laboratorium bank mini syariah UNISBA, sebagai bahan informasi dan pembanding dilakukan pula pengamatan pada perguruan tinggi lain yang memiliki laboratorium bank mini syariah. Penjelasan pemberdayaan pada masing-masing perguruan tinggi dapat dijelaskan sebagai berikut:

\section{Universitas Islam Negeri (UIN) Malang}

Laboratorium bank mini syariah di Universitas Islam Negeri (UIN) Malang didirikan pada bulan Maret 2016, dibawah koordinasi Fakultas Ekonomi. Pemberdayaan yang dilakukan di laboratorium bank mini syariah di perguruan tinggi ini dijelaskan sebagaimana berikut:

1. Pengalihan Kekuasaan, Kekuatan, dan Kemampuan

Fakultas Ekonomi UIN Malang memberikan kewenangan terhadap Kasi laboratorium untuk menjalankan proses pembelajaran pada tiap semesternya yang dibuktikan dengan memberikan kewenangan dalam :

a. Menentukan jadwal praktikum pada setiap semester dengan jumlah pertemuan sebanyak 2 minggu sekali per tim.

b. Mata kuliah yang diselenggarakan terdiri dari laboratorium bank mini 1 dan 2 . Dimana muatan mata kuliah laboratorium bank mini 1 berisi tentang lembaga mikro perbankan syariah, sedangkan laboratorium bank mini 2 berisi tentang simulasi di perbankan syariah menggunakan software SALAM BRIS dari bank BRI Syariah.

c. Selain itu, ada pengalihan otoritas kepada dosen dan mahasiswa dalam pengelolaan lembaga yang didirikan di laboratorium yaitu lembaga elDinar dan laku pandai. Pengelola lembaga ini diserahkan kepada dosen dan mahasiswa terpilih.

d. Pembelajaran di laboratorium bank mini syariah dibantu oleh mahasiswa sebagai asisten laboratorium yang memiliki tugas membantu dosen dalam memberikan pengajaran kepada mahasiswa dan menjaga keamanan serta ketertiban laboratorium bank mini dengan cara menyusun jadwal piket.

2. Menjadi Berdaya

Kemampuan mahasiswa dalam mengoperasikan aplikasi SALAM BRIS dan software yang dipakai di elDinar memberikan peningkatan kepada kompetensi mahasiswa dalam menggunakan alat bantu. Sehingga ketika mahasiswa sudah terampil menggunakan software yang disediakan di laboratorium, mahaiswa terbaik diangkat menjadi pengelola elDinar dan laku pandai serta diangkat menjadi asisten laboratorium bank mini syariah. 
3. Dapat Membangun Aset Material Untuk Pembangunan Kemandirian

Laboratorium bank mini syariah UIN Malang telah dapat membangun aset material untuk pembangunan kemandirian yang diindikasikan dengan berdirinya mendirikan lembaga elDinar sebagai bentuk transaksi riill mahasiswa dalam mengelola keuangan syariah. Sumber dana funding diperoleh dari karyawan, mahasiswa dan dosen Fakultas Ekonomi sebagai support awal. Tabungan menggunakan akad wadiah dan deposito menggunakan akad mudharabah. Adapun untuk pembiayaan, disalurkan bagi mahasiswa yang memiliki usaha atau disebut dengan pembiayaan entrepreneur menggunakan akad mudharabah. Adapun besaran minimal deposito adalah sebesar Rp. 350.000,- setiap satu kelompok. Satu kelompok tersebut terdiri dari 7 orang sehingga masing-masing mahasiswa memberikan deposito sebesar Rp. 50.000,-. Sumber penerimaan awal diperoleh dari tabungan awal sebesar Rp. 50.000,- yang terdiri atas dana wakaf sebesar Rp. 10.000,- dan ujrah buku tabungan sebesar Rp. 5.000,-.

Proses analisis dilakukan pada mata kuliah bussines plan bekerjasama dengan dosen yang bersangkutan untuk menilai apakah pembiayaan itu layak atau tidak untuk dibiayai oleh lembaga elDinar dimana lembaga tersebut akan menyalurkan pembiayaan kepada kelompok yang memiliki simpanan deposito di elDinar karena deposito tersebut sebagai bentuk jaminan mahasiswa dalam pembiayaan usaha. Artinya sistem yang dipakai adalah dari mahasiswa dan untuk mahasiswa.

4. Dapat Membentuk Organisasi

Laboratorium bank mini syariah UIN Malang sudah membentuk organisasi lembaga keuangan mikro yang dikelola mahasiswa yaitu elDinar dan laku pandai.

5. Dapat Menentukan Pilihan Kelangsungan Hidup

Laboratorium bank mini syariah UIN Malang melakukan kerjasama dengan berbagai pihak untuk melanjutan kelangsungan hidupnya seperti dengan BRI Syariah dalam pengelolaan dana mahasiswa dengan menjadi agen laku pandai bank BRI Syariah.

\section{Universitas Islam Negeri (UIN) Sunan Ampel Surabaya}

Laboratorium bank mini syariah di Universitas Islam Negeri (UIN) Sunan Ampel Surabaya berada di bawah koordinasi Fakultas Syariah dan Fakultas Ekonomi dan Bisnis Islam. Pada tahun 2007 praktik secara riil dilakukan oleh laboratorium bank mini UIN Sunan Ampel dengan menggunakan konsep mini banking. Pemberdayaan yang dilakukan dapat dijelaskan sebagai berikut:

1. Pengalihan Kekuasaan, Kekuatan, dan Kemampuan

UIN Sunan Ampel Surabaya memberikan kekuasaan pengelolaan laboratorium kepada Kasi laboratorium yang sekaligus mengelola transaksi riil laboratorium. Pembelajaran di laboratorium dilakukan dengan sistem on job training selama 1 bulan. Adapun pengenalan mini banking syariah diperkenalkan kepada mahasiswa semester 3 dengan masa pembelajaran selama 1 minggu.

2. Menjadi Berdaya

Mulai tahun 2007 laboratorium bank mini syariah UIN Sunan Ampel telah melakukan praktik transaksi secara riil proses mini banking dimana sampai saat ini, mereka memiliki hampir 1/3 nasabah mahasiswa dari jumlah total keseluruhan mahasiswa UIN Sunan Ampel. Ini berarti bahwa mini banking ini sangat didukung oleh civitas akademika perguruan tinggi dimana nasabah bukan hanya dari mahasiswa Fakultas Syariah dan FEBI saja namun sudah meluas target pasarnya kepada seluruh 
civitas perguruan tinggi.

3. Dapat Membangun Aset Material Untuk Pembangunan Kemandirian

Laboratorium bank mini syariah UIN Sunan Ampel telah dapat membangun aset material untuk pembangunan kemandirian yang dapat diindikasikan dari mendirikan lembaga mini banking syariah yang memiliki produk simpanan berupa tabungan dan deposito serta produk pembiayaan dengan akad murabahah, ijarah dan qardhul hasan. Pembiayaan disalurkan kepada mahasiswa yang membutuhkan untuk membayar perkuliahan dengan menggunakan akad qardhul hasan dengan proses analisa data menghubungi orang tua nasabah melalui telepon. Jika mahasiswa mengajukan pembiayaan lebih dari 1 juta rupiah maka diwajibkan menyertakan jaminan berupa BPKB, surat pernyataan penahanan ijazah dan memiliki simpanan deposito. Selain itu pula ada rekomendasi dari dosen atau teman bahwa nasabah tersebut dapat mengembalikan dana pembiayaannya. Selain mahasiswa, karyawan dan dosen juga dapat mengakses pembiayaan dengan plafon di atas 150 juta rupiah.

4. Dapat Membentuk Organisasi

Laboratorium bank mini syariah UIN Sunan Ampel Surabaya sudah membentuk organisasi lembaga keuangan mikro yang dikelola mahasiswa yaitu BMS (Bank Mini Syariah).

5. Dapat Menentukan Pilihan Kelangsungan Hidup

Laboratorium bank mini syariah UIN Sunan Ampel Surabaya melakukan kerjasama dengan berbagai pihak untuk melanjutan kelangsungan hidupnya seperti melayani konsultasi bisnis syariah melalui Pusat Lembaga Konsultasi Bisnis Syariah, BMS (Bank Mini Syariah) dan UPIJAWA (Unit Pengelola Zakat, Infak dan Shodaqoh)

\section{Universitas Islam Malang (UNISMA)}

Pemberdayaan yang dilakukan di laboratorium bank mini syariah Universitas Islam Malang dilakukan sebagaimana berikut :

1. Pengalihan Kekuasaan, Kekuatan, dan Kemampuan

Pengeloaan laboratorium bank mini syariah dikelola oleh Fakultas Ekonomi UNISMA. Laboratorium ini disebut dengan laboratorium simulasi Operasional Keuangan Syariah (OKS). Simulasi ini bisa diakses oleh mahasiswa yang mengikuti mata kuliah Operasional Keuangan Syariah sebanyak 42 orang per kelas. Penjadualan dilakukan per tim yang masing-masing berisi 4-5 orang mahasiswa per tim. Tim tersebut akan berbagi peran menjadi teller, customer service dan bagian pembiayaan. Satu tim dapat bersimulasi selama 2 sampai 3 hari dalam menyelesaikan operasional perbankan syariah.

2. Menjadi Berdaya

Laboratorium simulasi operasional perbankan syariah diberdayakan dengan membentuk BMT. Pada tahun 2000 modal BMT sebesar Rp. 7.000.000,- dan pada tahun 2016 memiliki aset sebesar 4 miliar.

3. Dapat Membangun Aset Material Untuk Pembangunan Kemandirian

Kemandirian yang dilakukan laboratorium bank mini adalah dengan membentuk koperasi syariah yang berbadan hukum dan pengelolaannya diawasi oleh Otoritas Jasa Keuangan Syariah.

4. Dapat Membentuk Organisasi

Organisasi yang dibentuk adalah koperasi syariah al-Iqtishod. Kegiatan 
penerimaan dana diperoleh dari nasabah baik itu mahasiswa, karyawan, dosen atau masyarakat luas. Besaran iuran pokoknya adalah Rp. 250.000,- dan Rp. 100.000,- bagi nasabah pembiayaan. Adapun iuran wajib sebesar Rp. 2.500,- setiap bulannya dan dibayarkan selama satu tahun yang diambil dari SHU (Sisa Hasil Usaha). Adapun produk pembiayaan yang dilakukan antara lain pembiayaan kuliah dengan jaminan laptop, tahan ijazah, perhiasan, atau BPKB, serta harus ada rekomendasi dari Wakil Dekan III.

5. Dapat Menentukan Pilihan Kelangsungan Hidup

Laboratorium Bank Mini Syariah UNISMA telah melakukan kerjasama dengan stakeholder diantaranya pelayanan diberikan kepada masyarakat selain kepada civitas akademika perguruan tinggi.

Dari penjelasan beberapa contoh pemberdayaan di atas, maka dapat ditarik kesimpulan bahwa semua laboratorium bank mini syariah di empat perguruan tinggi telah melakukan pemberdayaan laboratorium syariah masing-masing. Pemberdayaan yang dilakukan berbeda-beda satu dengan yang lainnya sehingga dapat menggambarkan model pemberdayaan sebagaimana berikut:

1. Model Pemberdayaan Sekunder

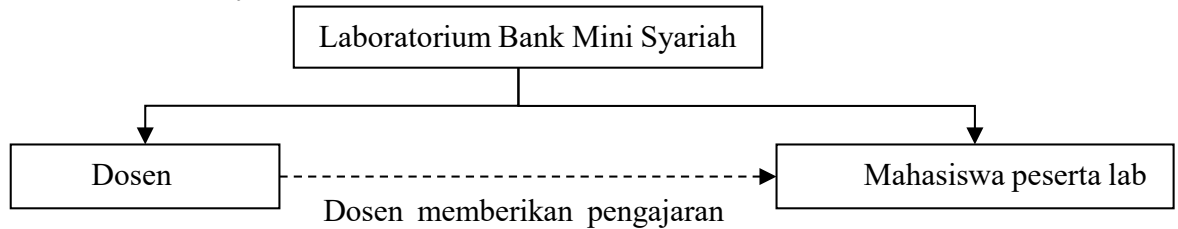

kepada mahasiswa secara

simulasi saja tanpa praktik riil

Gambar 2. Model Pemberdayaan Sekunder

2. Model Pemberdayaan Primer Internal Mahasiswa

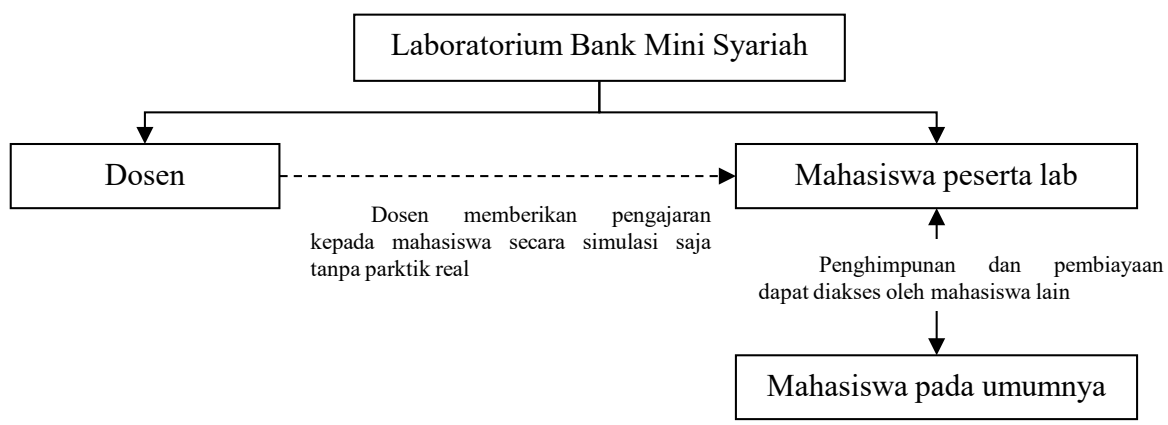

Gambar 3. Model Pemberdayaan Primer Internal mahasiswa

Pada model kedua dipraktikkan model pemberdayaan sebagaimana yang dilakukan oleh laboratorium bank mini syariah UIN Malang. 
3. Model Pemberdayaan Primer Internal Dosen dan Mahasiswa

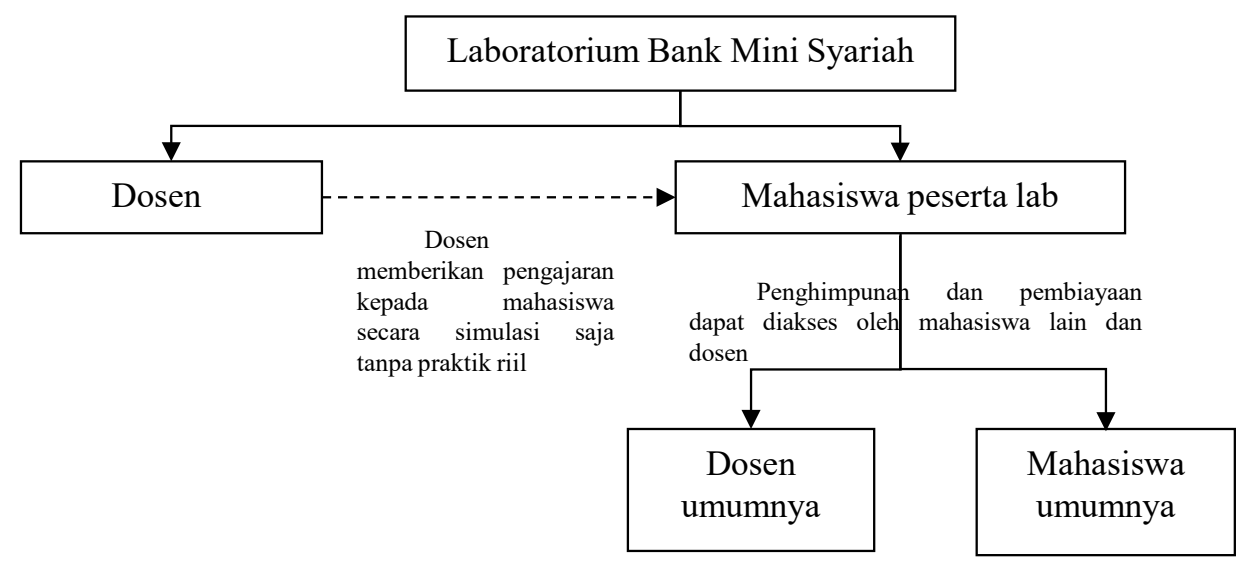

Gambar 4. Model Pemberdayaan Primer Internal Dosen dan Mahasiswa

Model ini diterapkan oleh laboratorium bank mini syariah UNISBA dan UIN Sunan Ampel Surabaya.

4. Model Pemberdayaan Primer Eksternal

Model ini diterapkan oleh laboratorium bank mini syariah UNISMA dengan mendirikan koperasi syariah berbadan hukum dan melayani pelayanan bagi civitas akademika UNISMA dan masyarakat luas.

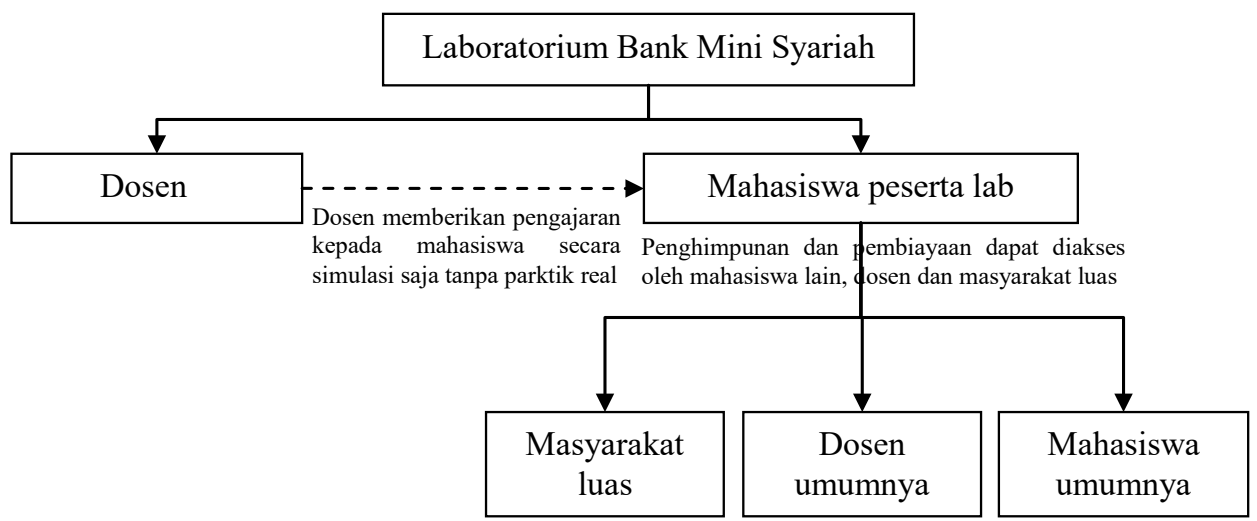

Gambar 5. Model Pemberdayaan Primer Eksternal

Berdasarkan penjelasan di atas, maka domain pemberdayaan laboratorium bank mini syariah di empat perguruan tinggi memiliki hubungan semantic sebagai elemen dengan rincian domain antara lain pengalihan kekuasaan, kekuatan, dan kemampuan; menjadi berdaya; dapat membangun aset material untuk pembangunan kemandirian; dapat membentuk organisasi dan dapat menentukan pilihan kelangsungan hidup. Adapun domain laboratorium bank mini syariah memiliki hubungan semantic sebagai 
fungsi dengan rincian domain pengembangan keterampilan motorik dalam transaksi riil keuangan di lapangan dengan bentuk penghimpunan dan penyaluran dana. Memiliki fungsi rincian domain sebagai pengembangan kompetensi bidang intelektual dalam proses simulasi di dalam laboratorium dan memberikan pelayanan kepada masyarakat umum yang hanya dilakukan oleh laboratorium bank mini syariah UNISMA.

Dengan demikian, model pemberdayaan laboratorium bank mini syariah dapat dilakukan dengan salah satu dari empat model di atas secara bertahap. Artinya bahwa model pemberdayaan primer eksternal dilakukan dengan menjadi lembaga keuangan mikro syariah yang berbadan hukum dan dapat membantu seluruh masyarakat dalam pendanaan atau pembiayaan guna meningkatkan sektor riil. Oleh karena itu, dua perguruan tinggi yaitu UNISBA dan UIN Sunan Ampel dapat mengembangkan lembaga mikro syariahnya lebih luas dan pada akhirnya dapat memberikan pelayanan kepada masyarakat agar sosialisasi kepada masyarakat terkait literasi keuangan syariah dapat tersampaikan dengan baik.

\section{KESIMPULAN}

Berdasarkan pembahasan sebelumnya dapat disimpulkan bahwa model pemberdayaan laboratorium bank mini syariah di perguruan tinggi memiliki empat model yaitu 1). Model pemberdayaan sekunder, 2). Model pemberdayaan primer internal mahasiswa, 3). Model pemberdayaan primer internal mahasiswa dan dosen, dan 4). Model pemberdayaan primer eksternal. Model pemberdayaan laboratorium ini berdasarkan pengamatan pada empat perguruan tinggi di Jawa yaitu UNISBA, UNISMA, UIN Malang dan UIN Sunan Ampel Surabaya.

UIN Malang menerapkan model pemberdayaan primer internal mahasiswa, UNISBA dan UIN Sunan Ampel Surabaya menerapkan model pemberdayaan primer internal mahasiswa dan dosen, dan UNISMA menerapkan model pemberdayaan primer eksternal. Dari domain pemberdayaan, semua perguruan tinggi memiliki hubungan semantic antara rincian domain lima elemen pemberdayaan, sedangkan domain laboratorium bank mini syariah, hanya satu perguruan tinggi yang memiliki ketiga fungsi dari rincian domain di atas yaitu UNISMA.

\section{DAFTAR PUSTAKA}

Adimihardja, K., \& Hikmat, H. (2001). Participatory Research Appraisal: Dalam Pelaksanaan Pengabdian Kepada Masyarakat. Humaniora Utama Press. Bandung.

Alamsyah, H. (2012). Perkembangan dan Prospek Perbankan Syariah Indonesia: Tantangan dalam Menyongsong MES 2015. IAEI.

Caralay, S. (2014). Repository UPI. Diambil kembali dari Model layanan perpustakaan sekolah luar biasa: http://repository.upi.edu/11779/11/T_PKKH_1104495_Chapter2.pdf

Fauziah, E., Senjiati, I. H., \& Malik, Z. A. (2016). Penerapan Program Corporate Social Responsibility Pendidikan di Perbankan Syariah. Prossiding SnaPP 2016 Sosial, Ekonomi, dan Humaniora (hal. 41-48). Bandung: LPPM UNISBA. Diambil kembali dari http:// proceeding.UNISBA.ac.id/index.php/sosial/article/view/54/pdf

Ghofur, A. (2015). Dampak Kemitraan Bank Syariah Mandiri Cabang Gresik terhadap Kinerja BMT (Studi Kasus BMT Mandiri Sejahtera Kabupaten Gresik. JEBIS 1 (2).

Hadi, A. P. (2009). Konsep Pemberdayaan, Partisipasi dan Kelembagaan dalam Pembangunan. Artikel. Yayasan Agribisnis/Pusat Pengembangan Masyarakat Agrikarya (PPMA) 
Hamdani, A. D., \& Kurniatanty, I. (2008). Manajemen dan Teknik Laboratorium. Yogyakarta: Universitas Islam Negeri Yogyakarta.

Hornby, A.S. (2010). Oxford advanced learner's dictionary (8th ed.). Oxford: Oxford University Press.

Istikanah. (2014). Optimalisasi Peran Laboratorium Bank Syariah sebagai Bentuk Edukasi pada Civitas Akademika Perguruan Tinggi terkait Perbankan Syariah. Malang: Fakultas Ekonomi Universitas Negeri Malang.

Ludviana, D. A. (2012). Peran Serta Laboratorium Bank Mini Pionir Untuk Mendukung Pengelolaan Keuangan Sekolah. Malang: Universitas Negeri Malang.

Majid, A. (2013). Strategi Pembelajaran. Bandung: PT. Remaja Rosdakarya.

Otoritas jasa Keuangan. (2015). Road Map Perbankan Syariah 2015-2019. Diambil dari http:// www.ojk.go.id/id/kanal/syariah/berita-dankegiatan/publikasi/Documents/roadmappbs_2015-2019.pdf

Saifulloh, M. (2016). Pengaruh Pembelajaran Praktikum Laboratorium Keuangan (Bank Mini) Terhadap Skill Mahasiswa Keuangan Islam UIN Sunan Kalijaga. Fakultas Ekonomi dan Bisnis Islam.

Spradley, J. P. (2007). Metode Etnografi. Edisi 2 Cet. 1. Yogyakarta: Tiara Wacana.

Sugiyono. (2015). Metode Penelitian Manajemen. Bandung: Alfabeta.

Sumodiningrat, G. (1997). Pembangunan Daeran dan Pengembangan Masyarakat. Jakarta: Bina Rena Pariwarna.

Zuhroh, I. (2012 ). Penguatan Laboratorium Bank Mini Syariah untuk Mendukung Perkembangan Industri Keuangan Syariah. Ekonomika-Bisnis 3 (1), 13-28. 